\title{
GREENHOUSE GASES, GLOBAL WARMING AND GLACIER ICE MELT IN NEPAL
}

\author{
Krishna B. Karki, Ph. D ${ }^{1}$
}

\begin{abstract}
Concentration of greenhouse gases has been found increasing over the past centuries. Carbon dioxide (9-26\% greenhouse effect), methane (4-9\%), and nitrous oxide (3-6\%) are the three principal greenhouse gasses though chloroflourocarbon and halon are also included as greenhouse gasses but are in very small greenhouse effect. These gasses are produced both from natural process and anthropogenic activities. Increase of these greenhouse gasses from nature in the atmosphere is mainly from the decomposition of organic matter, nitrification and denitrification of nitrogen including respiration by the plants. Anthropogenic production of carbon dioxide is from burning of fossil fuel whereas for methane livestock and paddy cultivation. Agricultural activities mainly use of mineral fertilizer is responsible for nitrous oxide emission. Increase of these gasses in atmosphere increases temperature that further accelerates evaporation of moisture from the earth's surface. Increase in water vapor in the atmosphere will further aggravate temperature rise. This increase in atmospheric temperature has direct effect in the melting of glacier ice in Nepalese Himalaya. Melting of ice and increases water volume in the glacier fed rivers and glacier lakes. Rise in water volume beyond its capacity the glacial lakes bursts releasing millions of cubit meters of water and takes million of lives and properties downstream. If this continues there will be no more ice left in the Himalaya and in the long run all the rivers of Nepal will go dry and country will face serious water shortage for drinking, irrigation and other purposes.
\end{abstract}

\section{Introduction}

\section{Greenhouse Effect and Greenhouse Gases}

When sunlight reaches the surface of the earth, some of it is absorbed and warms the earth. Because the earth's surface is much cooler than the sun, it radiates energy at much longer wavelengths than does the sun. The atmosphere absorbs these longer wavelengths more effectively than it does the shorter wavelengths from the sun. The absorption of this long wave radiant energy warms the atmosphere; the atmosphere also is warmed by transfer of sensible and latent heat from the surface. Greenhouse gases also emit long wave radiation both upward to space and downward to the surface. The downward part of this long wave radiation emitted by the atmosphere is the "greenhouse effect." Greenhouse gases (GHG) are components of the atmosphere that contribute to the Greenhouse effect. Some greenhouse gases occur naturally in the atmosphere, while others result from human activities such as burning of fossil fuel and coal. Greenhouse gases include water vapor, carbon dioxide, methane, nitrous oxide, and ozone.

The major natural greenhouse gases are water vapor, which causes about 36-70\% of the greenhouse effect on earth (not including clouds); carbon dioxide, which causes 9-26\%; methane, which causes $4-9 \%$, and ozone, which causes 3-7\% (IPCC 2001). It is not possible to state that a certain gas causes a certain percentage of the greenhouse effect, because the

\footnotetext{
${ }^{1}$ Chief Soil Scientist, Soil Science Division, NARC, Khumaltar, Lalitpur, Nepal Phone: 5521149, Email: karkikb@narc.gov.np
} 
influences of the various gases are not additives. Other greenhouse gases include, but are not limited to, nitrous oxide, sulfur hexafluoride, hydrofluorocarbons, perfluorocarbons and chlorofluorocarbons.

It is worth noting that late $19^{\text {th }}$ century scientists experimentally discovered that $\mathrm{N}_{2}$ and $\mathrm{O}_{2}$ did not absorb infrared radiation (called, at that time, "dark radiation") and that $\mathrm{CO}_{2}$ and many other gases did absorb such radiation. It was recognized in the early $20^{\text {th }}$ century that the known major greenhouse gases in the atmosphere did cause the earth's temperature to be higher than it would have been without the greenhouse gases. The measurement at various place of the world has proved that global mean annual surface temperatures have increased between 0.3 and $0.6^{\circ} \mathrm{C}$ during the last 150 years (IPCC 2001a.).

\section{Causes of Greenhouse Gas Emissions}

Greenhouse gas emissions from industry, transportation and agriculture are very likely the main cause of recently observed global warming. Global anthropogenic greenhouse gas emissions are broken down into 8 different sectors for the year 2000 (IPCC 2001). The concentrations of several greenhouse gases have increased over time. Human activity increases the greenhouse effect primarily through release of carbon dioxide. In nature these gases are emitted, which cannot be stopped but human activities influences and accelarate other greenhouse gases that are also important because even in the small amount they creat serious problem. Some of the main sources of greenhouse gases due to human activity include:

- burning of fossil fuels, firewood and deforestation leading to higher carbon dioxide concentrations. In Nepalese condition uncontrolled bush fire that devastate a large area every year also adds enourmous amount of $\mathrm{CO}_{2}$;

- livestock and paddy rice farming, land use and wetland changes, pipeline losses, and covered vented landfill emissions leading to higher methane atmospheric concentrations. Many of the newer style fully vented septic systems that enhance and target the fermentation process also are major sources of atmospheric methane;

- use of chlorofluorocarbons (CFCs) in refrigeration systems, and use of CFCs and halons in fire suppression systems and manufacturing processes;

- agricultural activities, including the use of fertilizers, that lead to higher nitrous oxide emission.

\section{Climate Change}

Measurements from Antarctic ice cores show that just before industrial emissions began, atmospheric $\mathrm{CO}_{2}$ levels were about 280 parts per million by volume (ppm; the units $\mu \mathrm{L} / \mathrm{L}$ are occasionally used and are identical to parts per million by volume). From the same ice cores it appears that $\mathrm{CO}_{2}$ concentrations stayed between 260 and $280 \mathrm{ppm}$ during the preceding 10,000 years (Archer et. al. 998). Studies using evidence from stomata of fossilized leaves suggest greater variability, with $\mathrm{CO}_{2}$ levels above $300 \mathrm{ppm}$ during the period 7,000-10,000 years ago, though others have argued that these findings more likely reflect calibration/contamination problems rather than actual $\mathrm{CO}_{2}$ variability (Barnola et al, 1995).

Since the beginning of the Industrial Revolution, the concentrations of many of the greenhouse gases have increased. The concentration of $\mathrm{CO}_{2}$ has increased by about $100 \mathrm{ppm}$ (i.e., from $280 \mathrm{ppm}$ to $380 \mathrm{ppm}$ ). The first $50 \mathrm{ppm}$ increase took place in about 200 years, from the start of the Industrial Revolution to around 1973; the next $50 \mathrm{ppm}$ increase took place in about 33 years, from 1973 to 2006. Many observations are available on line in a variety of Atmospheric Chemistry Observational Databases especially in the $\mathrm{CO}_{2}$ concentration 
in the atmosphere revealed that some thousand of year ago (4000 to 10,000 years ago) 380 $\mathrm{ppm}$ of $\mathrm{CO}_{2}$ is trapped in the ice (Barnola et al 1987). When ice in the arctic or in the Himalaya is melted all that $\mathrm{CO}_{2}$ that has been trapped in ice will be released to the atmosphere adding its concentration there by increase in atmospheric temperature.

\section{Global Warming Potential (GWP)}

Global warming potential (GWP) is a measure of how much a given mass of greenhouse gas is estimated to contribute to global warming. It is a relative scale which compares the gas in question to that of the same mass of carbon dioxide (whose GWP is by definition 1). A GWP is calculated over a specific time interval and the value of this must be stated whenever a GWP is quoted or else the value is meaningless. Just as radiative forcing provides a simplified means of comparing the various factors that are believed to influence the climate system to one another, Global warming potentials (GWPs) are one type of simplified index based upon radiative properties that can be used to estimate the potential future impacts of emissions of different gases upon the climate system in a relative sense. GWP is based on a number of factors, including the radiative efficiency (heat-absorbing ability) of each gas relative to that of carbon dioxide, as well as the decay rate of each gas (the amount removed from the atmosphere over a given number of years) relative to that of carbon dioxide.

The Intergovernmental Panel on Climate Change (IPCC) provides the generally accepted values for GWP, which changed slightly between 1996 and 2001 (Orlemanns et. al. 2000). An exact definition of how GWP is calculated is to be found in the IPCC's 2001 Third Assessment Report. The GWP is defined as the ratio of the time-integrated radiative forcing from the instantaneous release of $1 \mathrm{~kg}$ of a trace substance relative to that of $1 \mathrm{~kg}$ of a reference gas:

$$
G W P(x)=\frac{\int_{0}^{T H} a_{x} \cdot[x(t)] d t}{\int_{0}^{T H} a_{r} \cdot[r(t)] d t}
$$

where: $\mathrm{TH}$ is the time horizon over which the calculation is considered; $\mathrm{a}_{\mathrm{x}}$ is the radiative efficiency due to a unit increase in atmospheric abundance of the substance (i.e., $\mathrm{Wm}^{-2} \mathrm{~kg}^{-1}$ ) and $[x(t)]$ is the time-dependent decay in abundance of the substance following an instantaneous release of it at time $t=0$. The denominator contains the corresponding quantities for the reference gas (i.e. $\mathrm{CO}_{2}$ ). The radiative efficiencies $a_{x}$ and $a_{r}$ are not necessarily constant over time. While the absorption of infrared radiation by many greenhouse gases varies linearly with their abundance, a few important ones display nonlinear behaviour for current and likely future abundances (e.g., $\mathrm{CO} 2, \mathrm{CH} 4$, and N2O). For those gases, the relative radiative forcing will depend upon abundance and hence upon the future scenario adopted.

Since all GWP calculations are a comparison to $\mathrm{CO}_{2}$ which is non-linear, all GWP values are affected. Assuming otherwise as is done above will lead to lower GWPs for other gases than a more detailed approach would. Some of the GWP values related to some gases are mentioned in Table 1. 
Table 1. GWP Values and Lifetimes from IPCC Third Assessment Report (TAR)

\begin{tabular}{|c|c|c|c|c|}
\hline \multirow[t]{2}{*}{ Gas } & \multirow[t]{2}{*}{ Lifetime (years) } & \multicolumn{3}{|c|}{$\begin{array}{l}\text { GWP } \\
\text { Time horizon }\end{array}$} \\
\hline & & 20 years & 100 years & 500 year \\
\hline Methane & 12 & 62 & 23 & 7 \\
\hline Nitrous oxide & 114 & 275 & 296 & 156 \\
\hline $\begin{array}{l}\text { HFC-134a } \\
\text { (hydrofluorocarbon) }\end{array}$ & 13.8 & 3300 & 1300 & 400 \\
\hline $\begin{array}{l}\text { HFC-23 } \\
\text { (hydrofluorocarbon) }\end{array}$ & 260 & 9400 & 12000 & 10000 \\
\hline sulfur hexafluoride & 3200 & 15100 & 22200 & 32400 \\
\hline
\end{tabular}

Source: IPCC. (2001)

\section{Glacier Flood Threat in Nepal}

There are 19 glacial fed rivers in Nepal with 3252 glaciers (Table 2). Area covered by these glaciers is $5324 \mathrm{KM}^{2}$ and total ice reserve is $480.48 \mathrm{M}^{3}$. Every summer a part of snow melts and adds up in the next winter. This way the ice is recycled. Glacial lakes created by melting glaciers can overflow, releasing several thousand cubic meters of water per second along stream channels. We have observed several floods down stream due to increase in water volume of many rivers. Climate scientists in Nepal have warned that poor coordination of research and an inactive early warning system are putting Nepal's people at risk of flooding caused by melting glaciers. There have been more than 15 of these floods in Nepal, occurring at a frequency of one every two to five years, according to the Nepalese Department of Hydrology and Meteorology (DHM). This has been attributed to global warming, which, according to DHM research, is increasing temperatures in the Nepalese Himalayas by 0.04 degrees Celsius per year (Mool et al 2001).

Tsho Rolpa is one of the biggest and potentially dangerous glacier lakes in Nepal. Scientists predict that an outburst flood would endanger thousands of lives and cost millions of dollars in economic losses. The DHM has already established an early warning system consisting of a network of sensors and sirens in 19 villages downstream of Tsho Rolpa. But monitoring system has yet to be put into use because Nepal is concentrating on the establishment of peace after years of internal conflict. Glacial lake outburst floods first attracted scientific and government attention when the Dig Tsho glacier in Nepal's Khumbu region flooded in 1985.

The disaster completely destroyed a hydropower plant and washed away agricultural land, bridges and houses over a distance of 42 kilometers. Future disasters around the Himalayas will include 'floods, droughts, land erosion, biodiversity loss and changes in rainfall and the monsoon'.

Table 2. River System and the Glacier Ice Reserve in Nepal

\begin{tabular}{|l|l|l|l|}
\hline Name of River & Numbers of Glaciers & Area in $\mathrm{KM}^{2}$ & Ice Reserve $\mathrm{KM}^{3}$ \\
\hline Mahakali & 87 & 143.33 & 10.06 \\
\hline Seti & 134 & 294.13 & 24.48 \\
\hline Kawari & 39 & 53.33 & 2.39 \\
\hline Humla & 424 & 534.53 & 36.06 \\
\hline Tila & 58 & 54.69 & 3.75 \\
\hline
\end{tabular}




\begin{tabular}{|l|l|l|l|}
\hline Mugu & 254 & 220.39 & 12.52 \\
\hline Bheri & 452 & 583.4 & 47.77 \\
\hline Kali Gandaki & 399 & 562.67 & 51.65 \\
\hline Seti & 61 & 164.48 & 16.88 \\
\hline Marshyangdi & 311 & 614.31 & 54.99 \\
\hline Burhi Gandaki & 180 & 442.14 & 40.4 \\
\hline Indrawati & 18 & 22.98 & 1.44 \\
\hline Trishuli & 74 & 246.65 & 27.47 \\
\hline Sunkoshi & 23 & 74.56 & 7.19 \\
\hline Tamakoshi & 80 & 109.69 & 10.37 \\
\hline Likhu & 28 & 30.19 & 1.94 \\
\hline Dudhkoshi & 278 & 482.2 & 51.01 \\
\hline Arun & 91 & 216.07 & 23.47 \\
\hline Tamor & 261 & 474.15 & 56.64 \\
\hline Total & 3252 & 5323.89 & 480.48 \\
\hline
\end{tabular}

Source: Mool et. al. 2001

Eventually, the Himalayan glaciers will shrink so much their melt waters will dry up, say scientists. Catastrophes like flooding will die out. At the same time, rivers fed by these melted glaciers will turn to trickles. Drinking and irrigation water will disappear. Hundreds of millions of people will be affected. There are several studies conducted and still running in Nepalese glaciers such as British, Germans, Japanese and Norwegians. They warn that there is a short-term danger of too much water coming out the Himalayas and a greater long-term danger of there not being enough. It is pinpointed that the cause: global warming.

According to Nature, temperatures in the region have increased by more than $1{ }^{\circ} \mathrm{C}$ recently and are set to rise by a further $1.2^{\circ} \mathrm{C}$ by 2050 and by $3^{\circ} \mathrm{C}$ by the end of the century (Vuichard and Zimmermann; 1987). This heating has already caused 24 of Bhutan's glacial lakes to reach 'potentially dangerous' status, according to government officials. Nepal is similarly affected. The scientists engaged in glacial studies in Nepal warn that glacier lake catastrophe happened once in a decade. There was such event 50 years ago and is expected by 2010 (Mool at el 2001). Small glacial lake catastrophe will happen every year. An example of the impact is provided by Luggye Tsho, in Bhutan, which burst its banks in 1994, sweeping 10 million cubic meters of water down the mountain. It struck Panukha, 50 miles away, killing 21 people.

Not only villages are under threat: Nepal has built an array of hydro-electric plants and is now selling electricity to India and other countries. But these could be destroyed in coming years. A similar lake burst near Machu Picchu in Peru recently destroyed an entire hydro-electric plant. The same thing is waiting to happen in Nepal.

Even worse, when Nepal's glaciers melt, there could be no water to drive the plants. 'The region faces losing its most dependable source of fresh water. A Greenpeace suggested that the region is already experiencing serious loss of vegetation. In the long term, starvation is a real threat.

Scientific analysis has shown that annual temperature increase in the Trans-Himalaya is on average 0.09 degrees Celsius. The annual temperature increase throughout Nepal is 0.06 degrees Celsius. This high increase in temperature has resulted in melting of glaciers, formation of glacial lakes, which have resulted in glacial lake outburst floods (GLOF). Sixty- 
seven percent of glaciers are retreating in the Himalayas and climate change has been identified as the major factor (Mool et al, 2001).

\section{Mitigation Possibilities}

\section{Population Control}

Increase in population demand higher amount of food, shelter and clothing. All these come from the natural resources such as land. Land provides natural resources and that is overexploited in our country. The population of Nepal at this time is at the rate of $2.3 \%$ per annum. If this rate continues more and more area will be covered to settle theses people and provide the basis needs. Mostly forest land will be denudated and there will be no other means to trap the $\mathrm{CO}_{2}$ emitted by natural sources increasing its concentration in the atmosphere there by increase atmospheric temperature. Therefore the rate of population is very high and we should reduce our population.

\section{Follow Clean Development Mechanisms (CDM)}

Country will have to implement the CDM programs reducing greenhouse gasses emissions to the minimum level. In Nepal Biogas extension program is gaining popularity in this mechanism. Similar programs in agriculture and forestry sectors will have to be implemented.

\section{Use of Fossil Fuels that Produce the Least Greenhouse Gases}

Vehicle and other combustion fuel that are available in Nepal are mostly contaminated such as petroleum products and coal. Low quality fuels emit more greenhouse gasses. So strict monitoring mechanisms should be developed and followed to stop adulteration of the petroleum products. Only clean fuel should be used.

\section{Burning Waste Methane}

In many places waste has been dumped with out any care. Even the municipal dumping sites are not we designed for burning of the methane that is produced from the dumping sites. There should be enough pipeline laid out to collect the methane and supply to the nearby residence that could partly supplement the fuel requirement of the locality. If not it should be burnt on site. Methane has been found escaping even from the dung-heap that is piled up around farmers' animal sheds. These heaps should be well aerated to developed aerobic decomposition rather fermentation and reduce methane generation.

\section{Alternative Energy Sources}

Firewood is a major carbon dioxide emitter in Nepal because over $90 \%$ of the energy comes up from bio-fuel. So reduce the use of this firewood energy and develop alternative energy such as hydropower, solar and wind energy including biogas.

\section{Carbon Sequestration}

Carbon sequestration is another important topic of these days to reduce greenhouse gas emission especially $\mathrm{CO}_{2}$. Increase soil organic matter by giving emphasis to organic farming. The other sequestration is to develop forest canopy use more $\mathrm{CO}_{2}$ by photosynthesis. Therefore give more emphasis to community forestry and forest plantation program.

\section{Conclusion}

Whether natural or anthropogenic, greenhouse gases are increasing in the atmosphere every day. The industrial countries emitted enormous amount of greenhouse gas from their 
industries every hour and blamed the developing nations for deforestation and burning firewood for the day to day energy. Voice raised by scientists around the world was completely ignored. They realized when the arctic ice started melting and sea beds rising. If this problem continues, as it is now, the coastal area especially of the developing nations like Bangladesh, India and the Caribbean Islands will be seriously affected. It is feared that Maldives will be completely under water. Although Nepal does not own any coastal area rise in atmospheric temperature will melt all the ice and the $480 \mathrm{~m}^{3}$ ice reserves will be lost in a short span of time devastating down stream taking thousands of lives and millions of properties. In the long run there will be no ice left to feed the snow fed rivers of Nepal that have supported lives of millions of people down stream. At the end this will also create serious drinking water shortage. So let us understand the problem of glacial ice melt and think seriously to mitigate the climate change and global warming.

\section{REFERENCES}

1. Archer, D., H. Kheshgi, and E. Maier-Reimer 1998, Dynamics of fossil fuel $\mathrm{CO}_{2}$ neutralization by marine $\mathrm{CaCO}_{3}$, Global Biogeochemical Cycles, 12 (2), 259-276,.

2. Barnola, J. M., D. Raynaud, S. Korotkevich, and C. Lorius, 1987, Vostok ice core provides 160,000-year record of atmospheric $\mathrm{CO}_{2}$, Nature, 329, 408-414,.

3. Barnola, J. M., M. Anklin, J. Porcheron, D. Raynaud, J. Schwander, and B. Stauffer, 1995, $\mathrm{CO}_{2}$ evolution during the last millennium as recorded by Antarctic and Greenland ice, Tellus, 47B, 264-272,.

4. IPCC 2001. Climate Change 2001: The Scientific Basis. Contribution of Working IPCC. The Scientific Basis. Contribution of Working Group I to the Third Assessment Report of the Intergovernmental Panel on Climate Change. Cambridge University Press, Cambridge, UK, $881 \mathrm{pp}$.

5. IPCC 2001b. Climate Change 2001: Impacts, Adaptation, and Vulnerability. IPCC. Report of the Intergovernmental Panel on Climate Change. Cambridge University Press, Cambridge, UK, 781 pp.

6. Mool, P.K., Wangda, D., Bajracharya, S.R., Kunzang, K., Gurung, D.R., and Joshi, S.P. 2001. Inventory of glaciers, glacial lakes and glacial lake outburst floods: Bhutan. ICIMOD, Kathmandu, Nepal.

7. Vuichard, M. and Zimmermann, M. 1987. The 1985 catastrophic drainage of a moraine-dammed lake, Khumbu Himal, Nepal: cause and consequences. Mountain Research and Development 7(2):91-110. 